\title{
CONF-9502117--1
}

UCRL-JC-118883

PREPRINT

\section{Accurate Determination of Transparency Current in Packaged Semiconductor Lasers and Semiconductor Optical Amplifiers}

\author{
F.G. Patterson \\ S.P. Dijaili \\ R.J. Deri
}

This paper was prepared for submittal to

Nonlinear Waves and Their Applications

Dana Point, CA

February 23-25, 1995

November 1994

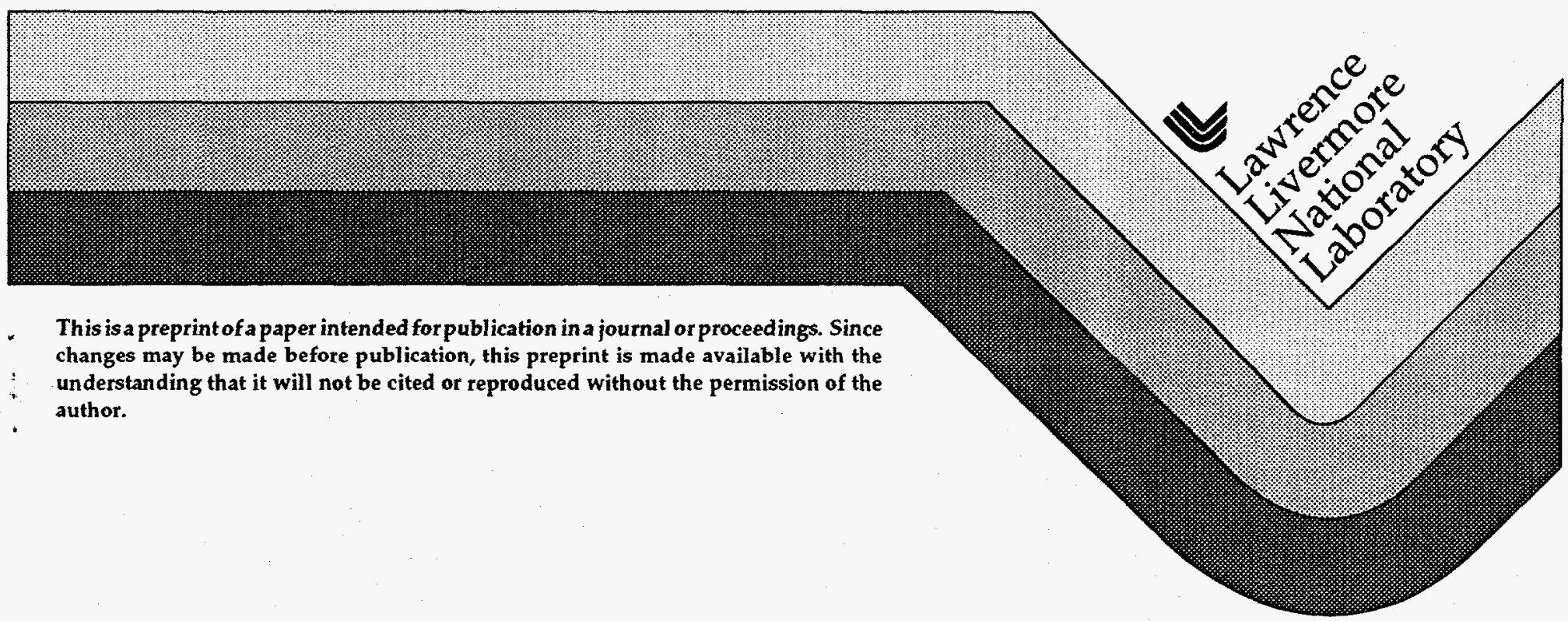

This is a preprint of a paper intended for publication in a journal or proceedings. Since changes may be made before publication, this preprint is made available with the understanding that it will not be cited or reproduced without the permission of the author. 


\section{DISCLAMMER}

This document was prepared as an account of work sponsored by an agency of the United States Government. Neither the United States Government nor the University of California nor any of their employees, makes any warranty, express or implied, or assumes any legal liability or responsibility for the eccuracy, completeness, or usefulness of any information, apparat us, product, or process disdosed, or represents that its use would not infringe privately owned rights. Reference herein to any specific commercial products, process, or service by trade name, trademark, manuf acturer, or otherwise, does not necessarily constitute or imply its endorsement, recommendation, or favoring by the United States Govemment or the University of California The views and opinions of authors expressed herein do nol necessarily state or reflect those of the United States Government or the University of Califomia, and shall not be used for advertising or product endorsem ent purposes. 


\section{DISCLAIMER}

Portions of this document may be illegible in electronic image products. Images are produced from the best available original document. 


\title{
ACCURATE DETERMINATION of TRANSPARENCY CURRENT in PACKAGED SEMICONDUCTOR LASERS and SEMICONDUCTOR OPTICAL AMPLIFIERS
}

F.G. Patterson, S.P. Dijaili and R. J. Deri

Lawrence Livermore National Laboratory

PO Box 808, Livermore, CA 94550

\begin{abstract}
We demonstrate a novel optical technique which can accurately measure the transparency current of packaged semiconductor lasers and optical amplifiers.
\end{abstract}




\title{
ACCURATE DETERMINATION of TRANSPARENCY CURRENT in PACKAGED SEMICONDUCTOR LASERS and SEMICONDUCTOR OPTICAL AMPLIFIERS
}

\author{
F.G. Patterson, S.P. Dijaili and R. J. Deri, \\ Lawrence Livermore National Laboratory, Livermore, CA 94550
}

The reliability of semiconductor laser diodes and related devices is a significant issue for their deployment in many applications [1,2], creating demand for device diagnostics applicable to packaged devices. Measurements of the transparency current density $\left(\mathrm{J}_{0}\right)$ in laser diodes and traveling-wave semiconductor optical amplifiers (SOAs) can provide such a diagnostic. It is essential, however, to measure $J_{0}$ on packaged devices, so that they can be characterized after aging or degradation. This precludes techniques requiring data from multiple devices (e.g., an ensemble with different lengths). $J_{0}$ is conventionally measured using a junction-voltage technique [3,4], in which an input optical signal induces a change in carrier density in the active region due to stimulated absorption or emission. The result is a voltage drop across the diode. At material transparency, the stimulated absorption is exactly balanced by the stimulated emission and the voltage drop goes to zero. Since the polarity of the voltage drop changes sign at current densities above $\mathrm{J}_{0}$, the optical input beam is typically modulated and lock-in amplification is employed to sensitively detect the polarity sign flip. Here we show that this technique is not reliable for certain types of laser structures, because the deduced $\mathrm{J}_{0}$ is strongly dependent on device packaging--that is, the measured $\mathrm{J}_{0}$ varies with the manner in which light is coupled into the diode waveguide. For packaged SOAs, we propose and demonstrate an alternative all-optical technique to overcome this problem. One important advantage of the optical method over the junction voltage method is that the actual device optically-guided mode is directly sampled. In the case of packaged semiconductor lasers, our all-optical method can complement the junction-voltage method to resolve device versus packaging degradation.

The essence of our all-optical technique for determining $J_{0}$ is shown in Fig. 1. A modulated (e.g., chopped at $350 \mathrm{~Hz}$ ) pump beam (at $\lambda_{\text {pump }}$ ) is coupled into facet 1 of a laser diode or SOA. Below the transparency current density $\left(\mathrm{J}_{0}\right)$ the pump beam will saturate the absorption and increase the transmission for a second laser beam (at $\lambda_{\text {probe }}$ ) or for the amplified spontaneous emission (ASE) generated in the test device. At current densities greater than $\mathrm{J}_{0}$ the pump beam will saturate the material gain and thereby decrease the transmission for other optical signals in the guided-wave device. At exactly $\mathrm{J}_{0}$, the pump beam does not modulate the other optical signal beams because neither saturable absorption or gain is present. Typically, the monitor signals are spectrally filtered in an optical spectrum analyzer (OSA, Hewlett-Packard 71451A) and detected with a lock-in amplifier. Since the semiconductor gain media are homogeneously-broadened, this method is largely insensitive to the wavelength of the detected

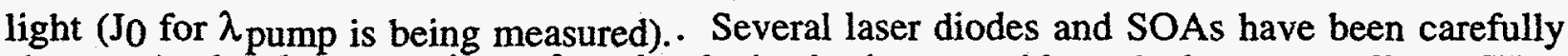
characterized and a comparison of results obtained using a tunable probe beam as well as ASE at different center wavelengths and bandwidths show that the technique is sensitive and reproducible.

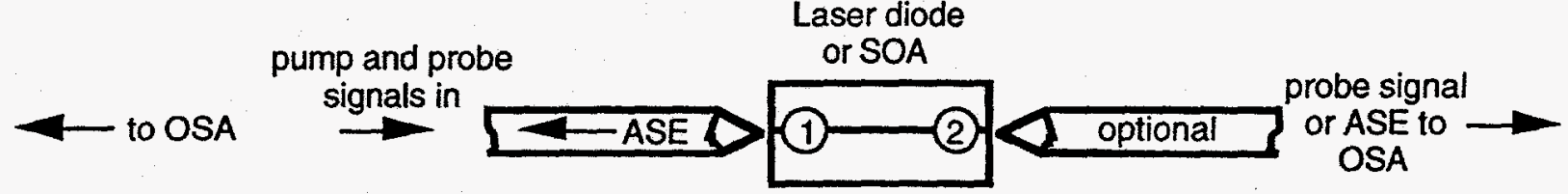

Fig. 1: Setup for measuring the transparency current of a laser diode or SOA using saturation-induced crosstalk. An optical spectrum analyzer (OSA) is utilized to spectrally filter the desired optical monitor signal: either forward or backward ASE or a weak probe beam ( $\lambda_{\text {probe }} \neq \lambda_{\text {pump }}$ ) in the forward direction. At $J_{0}$, no pump-induced modulation of the optical monitor signal occurs because neither saturable absorption or gain is present. 
Figure 2A shows optical spectra for our InGaAs/GaAs SQW GRINSCH semiconductor optical amplifier. Conically-polished single-mode fibers are aligned with precision translation stages and a pump beam is input into Facet 1 at a wavelength corresponding to the SOA gain peak $(891 \mathrm{~nm})$. A chip gain of $30 \mathrm{~dB}$ is obtained at $100 \mathrm{ma}$ for this $1 \mathrm{~mm}$ long device. Figure 2B shows a portion of the crosstalk versus current curve for this SOA. This plot (Fig. 2B), generated by detecting ASE at $922 \mathrm{~nm}$ (filter bandwidth=1 nm), shows that transparency occurs at $36 \mathrm{ma}$. For comparison, the junction-voltage technique indicates transparency at $28 \mathrm{ma}$. This is a moderate difference -- at a bias of $100 \mathrm{ma}$, a gain of $30 \mathrm{~dB}$ is inferred in the first case and $34 \mathrm{~dB}$ in the latter case. The $30 \mathrm{db}$ chip gain inferred from our new technique agrees well with the directly measured chip gain (fiber to fiber gain - coupling losses). The reason for the lower junction-voltage result is not fully understood. No significant change in $\mathrm{J}_{0}$ is observed for different positions of the input coupling fiber (this effect is structuredependent, see below).
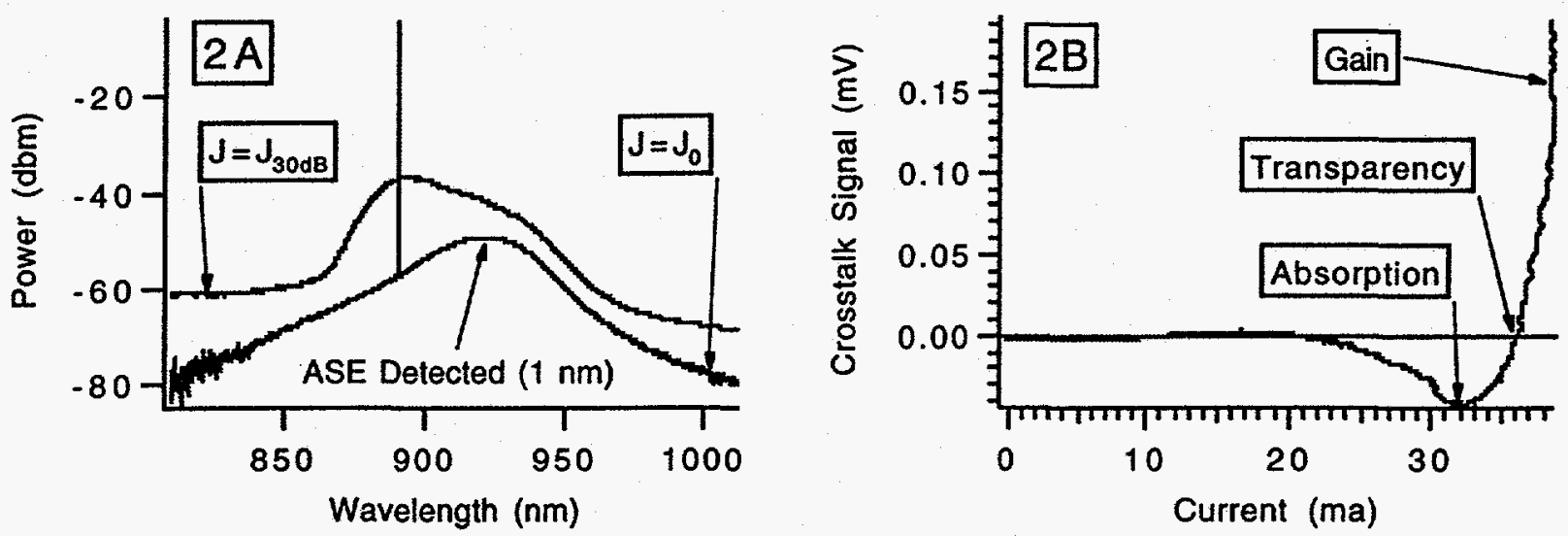

Fig. 2: A. Output spectra of SQW GRINSCH SOA with injected signal $(891 \mathrm{~nm})$ at transparency $\left(\mathrm{J}=\mathrm{J}_{0}\right)$ and at $30 \mathrm{~dB}$ chip gain $(\mathrm{J}=\mathrm{J} 30 \mathrm{~dB})$. B. Optical crosstalk as a function of the SOA bias current. At transparency, the SOAgenerated ASE ceases to be modulated by the chopped pump beam.

Figure 3A shows a comparison of the optical crosstalk and junction-voltage methods for determining $\mathrm{J}_{0}$ as a function of the lateral (in the plane of the junction) position of the input fiber coupled to a commercial laser diode (Sharp LT015). Note that when the input fiber is optimally coupled, the junction-voltage and optical crosstalk methods agree to better than $10 \%$. However, as the fiber is displaced in the plane of the junction, the optical method shows an increase in $\mathrm{J}_{0}$ whereas the junction-voltage method shows a large decrease.

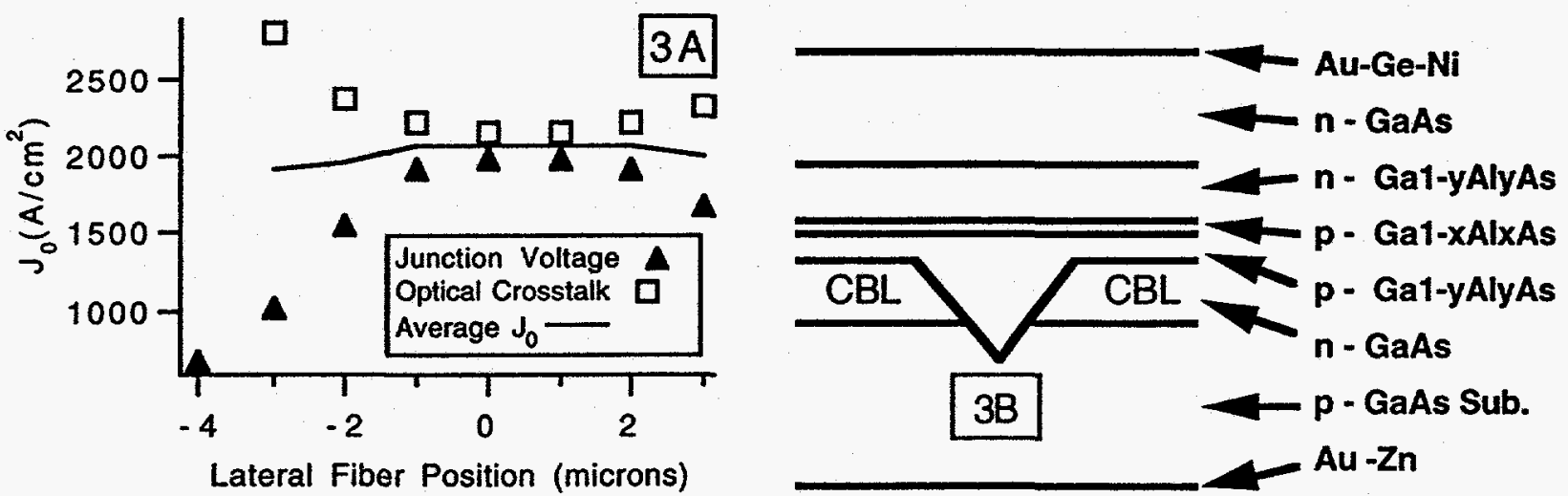

Fig. 3: A. Comparison of the junction-voltage and optical crosstalk methods for measuring transparency. B. Vchanneled substrate inner stripe (VSIS) laser diode. Sharp Corp., S. Yamamoto et al., Appl. Phys. Lett. 40, 972 (1982). 
One plausible argument for the transparency current dependence on horizontal displacement of the injected light is as follows. We refer to Fig. 3B showing the current blocking layers (CBL) of the Sharp laser diode. For the case of the optical method of determining $J_{0}$, the current density decreases laterally along the active region. These regions are pumped less so the overall current needs to be increased in order to reach transparency. The transparency current therefore increases with lateral displacement of the injected light. For the case of the junction-voltage method, the CBL region absorbs the injected light as it is horizontally displaced. The reverse bias junctions of the CBL act as photodiodes and thus a net excess of holes on the p-side of the active region tends to increase the forward current, thereby reducing the current needed from the external supply. This explanation requires further study. A very similar lateral Jo dependence has also been observed in another commercial laser diode which has a different device structure (Hitachi HLP1400, channel substrate planar).

The solid curve in Fig. 3A plots the average of the two transparency methods. This averaged parameter is relatively insensitive to the input fiber coupling and closely represents the true transparency current density. By making both measurements and tracking the changes over time, once can determine whether performance degradations originate in the device or the fibercoupled package. The optical technique for measuring transparency described here works well for both semicondductor lasers and optical amplfiers because access to only one optical facet is required. Additional information concerning the longitudinal distribution of gain anomalies (defects) may be obtained by comparing the measured $\mathrm{J}_{0}$ from opposite ends of a device with both facets accessible (details will be presented at the conference).

In conclusion, we have demonstrated a new all-optical technique for measuring the transparency current of semiconductor lasers and optical amplifiers. For SOAs, the technique is deemed superior to the junction voltage method because the measurement is performed on the actual optically guided-mode of interest. This has particular relevance to packaged devices since we have shown that in some structures the measured $\mathrm{J}_{0}$ is dependent upon the alignment of the fiber pigtail. Finally, monitoring $J_{0}$ over time using both the optical and voltage methods can provide a simple method for tracking the aging of packaged SOA and laser devices.

We thank Holly Petersen and Richard Combs for technical assistance. This work was performed under the auspices of the U.S. Department of Energy under contract W-7405-ENG48. at LLNL.

References: $\quad$ 1. L.F. DeChiaro, M. Robin, et al., J. Lightwave Technol. 11, 2057 (1993).

2. M.C. Wang, D.M. Hwang, et al., Appl. Phys. Lett. 64, 3145 (1994).

3. V.V. Luc, P.G. Eliseev, et al., J. Quantum Electron. 19, 1080 (1983).

4. A. Alping, B. Bentland, et al., Electron. Lett. 20, 794 (1984).

5. B. Saint-Cricq, S. Bonnefont, et al., Electron. Lett. 27, 865 (1991).

6. T.R. Chen, L.E. Eng, et al., Appl. Phys. Lett. 56, 1002 (1990). 